\title{
Pola Penggunaan Bahasa Melayu dalam Twitter Mantan Perdana Menteri Ke-enam, Dato' Seri Najib Razak
}

\author{
NUR FIRZA SHAFIQA KHALID \\ NORMALIZA ABD RAHIM \\ Universiti Putra Malaysia
}

\begin{abstract}
ABSTRAK
Media sosial Twitter adalah medium komunikasi yang kian dikenali saban tahun dan digunakan oleh banyak pihak termasuklah ahli politik untuk dijadikan wadah penyebaran dan penerimaan maklumat. Walau bagaimanapun, jika diperhatikan kebanyakkan ahli politik kurang menitikberatkan penguasaan dan penggunaan bahasa Melayu melalui ciapan yang dimuatnaik. Bertitik tolak dari permasalahan tersebut, kajian ini memberi tumpuan terhadap penggunaan bahasa yang terdapat di dalam ciapan Twitter ahli politik dengan melakukan beberapa penelitian. Kajian ini menjadikan akaun Twitter milik mantan Perdana Menteri Malaysia ke-enam, Datuk Seri Mohammad Najib bin Tun Haji Abdul Razak (@NajibRazak) sebagai sampel kajian berdasarkan kepada beberapa kriteria pemilihan. Di samping itu, kajian ini dijalankan berpaksikan Teori Analisis Wacana untuk mengenalpasti kandungan ciapan yang dimuat naik serta menganalisis pola penggunaan bahasa yang digunakan berdasarkan tema yang telah dikelaskan. Kajian ini menggunakan pendekatan kualitatif di mana kaedah analisis teks dipilih untuk menganalisis data. Hasil kajian menunjukkan beberapa kandungan yang dikenalpasti dalam penulisan ciapan @NajibRazak dan pola penggunaan bahasa dalam setiap ciapan yang berbeza-beza berdasarkan tiga kandungan yang telah ditetapkan. Penggunaan bahasa yang ditonjolkan di dalam penulisan ciapan Twitter menunjukkan bahawa bahasa yang digunakan oleh beliau mudah untuk difahami oleh pengguna Twitter mahupun masyarakat. Rumusan kajian menunjukkan bahawa mantan Perdana Menteri Ke-enam ini telah melakukan representasi wacana yang jelas terhadap penulisan ciapan di media sosial Twitter dan diharapkan kajian ini dapat membantu kajian-kajian mendatang khususnya di dalam bidang komunikasi politik.
\end{abstract}

Kata kunci: Media sosial, Twitter, ahli politik, analisis wacana, tekstual.

\section{Patterns of Malay Language Usage on Twitter of Former Sixth Prime Minister, Dato 'Seri Najib Razak}

\begin{abstract}
Nowadays, Twitter is increasingly used as a communication network by many parties, which includes politicians, to spread and receive information. However, if observed, most politicians are less concerned with the usage of Malay language when they upload a tweet. Deduced from this problem statement, this study focuses on the usage of Malay language found on politician's Twitter accounts, through various observations. Based on several selection criteria, this research studies the Twitter account of Malaysia's former sixth Prime Minister, Datuk Seri Mohammad Najib bin Tun Haji Abdul Razak (@NajibRazak). The study was conducted based on the Discourse Analysis Theory to identify the content of uploaded tweets, as well as to analyse the pattern of language used based on the themes that have been classified. This study adapts a qualitative approach in which the text analysis method is chosen to analyse the data. The results show that some of the content identified in $\mathrm{t} @$ NajibRazak's tweets and the pattern of language used in each speech varies based on the three that have been identified. The use of language highlighted in the writing of the subject's Twitter tweets shows that
\end{abstract}


the language he uses is easy to comprehend by Twitter users as well as the common community. In short, the study shows that the former Sixth Prime Minister has made a clear discourse analysis on the writing of tweets on Twitter and hopes that this study helps future research, especially in the field of political communication.

Keywords: Social media, Twitter, politicians, discourse analysis, textual.

\section{PENGENALAN}

Faktor utama media sosial memonopoli media penyampaian maklumat dan juga medium pembentukan hubungan sosial dalam kalangan manusia adalah kerana kepantasan dan mudah diakses. Media sosial menurut Cross (2013) dalam petikan Pratiwi (2020) adalah istilah yang menggambarkan pelbagai kecanggihan teknologi yang menghubungkan ramai orang dalam suatu kolaborasi, pertukaran maklumat, serta dapat berinteraksi melalui mesej berasaskan web. Sehubungan itu, pengguna media sosial dapat melakukan perkongsian idea, pemikiran dan maklumat yang merangkumi dokumen, gambar dan juga video melalui komputer atau telefon pintar melalui akses Internet (Dollarhide, 2019). Kajian ini menganalisis penggunaan bahasa Melayu dalam kalangan ahli politik di media sosial, iaitu, Twitter. Menurut Hidayatullah (2016), Twitter telah ditubuhkan oleh Jack Dorsey pada tahun 2006 dan masih berfungsi hingga sekarang. Dasarnya, penglibatan ideologi politik dan ahli politik dalam Twitter dapat dimanfaatkan oleh masyarakat untuk mengetahui isu politik semasa. Ahli politik turut boleh memanfaatkan Twitter sebagai alat untuk menyalurkan informasi semasa politik, meraih sokongan dan menyelami kehidupan rakyat meskipun tidak bersemuka (Harrera, 2016).

Walau bagaimanapun, kebanyakan ahli politik tidak menitikberatkan penggunaan bahasa Melayu terhadap ciapan yang ditulis kerana hanya mementingkan wacana politik yang mengandungi ideologi tertentu agar dapat mempengaruhi golongan sasaran (Agbo, Kadiri \& ljem, 2018). Berdasarkan kepada masalah ini, maka timbul keperluan untuk menganalisis pola penggunaan bahasa Melayu oleh ahli politik di Twitter. Hal ini penting untuk mengetahui keberkesanan komunikasi yang berlaku melalui penulisan ciapan di Twitter dalam kalangan ahli politik. Berdasarkan kepada beberapa kriteria yang telah ditetapkan seperti jumlah pengikut, pengalaman yang luas di dalam bidang politik dan penggunaan bahasa Melayu sebagai medium penulisan ciapan di Twitter, ahli politik yang dipilih sebagai sampel kajian ialah Datuk Seri Najib Razak iaitu mantan Perdana Menteri Malaysia ke-enam. Setakat 5 Julai 2019, akan Twitter @NajibRazak telah memiliki sebanyak 4.2 juta pengikut. Dari segi pengalaman, beliau telah menceburi dunia politik sejak berumur 23 tahun, setelah kematian bapanya yang merupakan mantan Perdana Menteri pertama iaitu Tun Abdul Razak. Di awal usianya, beliau telah memiliki sifat kepimpinan yang tinggi dan telah tercalon sebagai ahli parlimen Pekan untuk menggantikan tempat bapanya. Hal ini sekali gus, telah mencipta sejarah di Malaysia kerana beliau merupakan ahli parlimen yang paling muda pada waktu itu. Tidak hanya itu, seiring dengan waktu, beliau mula menyandang beberapa jawatan yang penting seperti Timbalan Menteri Tenaga, Telekom dan Pos; Menteri Besar; Timbalan Menteri Pendidikan serta telah memegang beberapa jawatan penting di dalam parti politik yang disertainya. Kejayaannya terus memuncak sehinggalah beliau berjaya memegang jawatan Timbalan Perdana Menteri pada tahun 2004 kemudian diangkat menjadi Perdana Menteri Malaysia keenam setelah memenangi pilihanraya pada tahun 2008. 
Seterusnya, rasional pemilihan akaun @NajibRazak adalah kerana beliau dilihat menggunakan bahasa Melayu dalam setiap penulisan ciapannya. Oleh hal yang demikian, ketiga-tiga justifikasi yang telah disenaraikan ini telah menunjukkan bahawa akaun Twitter Datuk Seri Najib Razak sesuai untuk dijadikan sampel kajian ini.

\section{BAHASA DAN POLITIK DALAM MEDIA SOSIAL}

Sa'adiah (2015) telah menjalankan satu kajian terhadap 200 orang responden untuk mengetahui pemilihan bahasa dalam komunikasi di media sosial. Kajian berkenaan mendapati bahawa sebanyak $47.2 \%$ menggunakan bahasa Melayu manakala sebanyak $42.8 \%$ menggunakan bahasa Inggeris di media sosial seterusnya diikuti oleh bahasa Cina, India dan lain-lain. Dengan erti kata lain, penggunaan bahasa yang sering digunakan di dalam media sosial akan ditentukan oleh pengguna media itu sendiri. Penyataan Sa'adiah (2015) mengenai penggunaan bahasa telah disokong oleh Fuzirah, Ahmad Aminuddin dan Bahiyah (2017) dan Normaliza, Awang Azman dan Nik Rafidah (2018) dengan menyatakan bahawa pengguna media sosial merupakan penentu terhadap penggunaan bahasa yang hendak ditulis di media sosial misalnya penggunaan bahasa campur, ejaan mahupun bahasa rojak. Tambahan lagi, kajian Fornara dan Lomicka (2019) turut bersetuju dengan kajian yang dijalankan oleh Sa'adiah (2015) serta Fuzirah, Ahmad Aminuddin dan Bahiyah (2017) dengan penambahan pernyataan bahawa media sosial adalah wahana terbaik untuk mempelajari dan mempraktikan sesuatu bahasa terutamanya dalam kalangan komuniti bahasa sekali gus dapat berkongsi maklumat antara satu sama lain.

Walau bagaimanapun, hasil kajian Fornara dan Lomicka (2019), serta Fuzirah, Ahmad Aminuddin dan Bahiyah (2017) dilihat bercanggah dengan hasil kajian yang dilakukan oleh Noraien dan Normaliza (2019). Kajian tersebut mendapati media sosial kurang sesuai untuk dijadikan platform pembelajaran bahasa kerana terdapat pelbagai isu negatif dalam penggunaan bahasa. Misalnya, pengguna menggunakan struktur ayat yang tidak baik dan kurang sopan. Malahan, dapatan Noraien dan Normaliza (2019) telah disokong oleh kajian Coltekin (2020) melalui satu analisis meliputi sebanyak 36,232 sampel ciapan Twitter yang dipilih secara rawak. Beliau mendapati sebanyak $77.9 \%$ bahasa kasar telah digunakan oleh masyarakat Turki sewaktu menulis di media sosial.

Selain itu, Ainal, Maizatul, Nasihah dan Noor Aida (2016) telah menjalankan kajian tentang kesantunan bahasa ketika berkomunikasi di media sosial. Kajian tersebut dijalankan untuk mengetahui penggunaan bahasa yang ditulis oleh khalayak sewaktu memberi maklum balas terhadap berita yang terdapat di Facebook. Kajian ini telah menggunakan pendekatan kualitatif dengan menganalisis komen-komen yang telah ditulis oleh khalayak. Hasil daripada analisis tersebut mendapati bahawa, terdapat sebilangan besar atau majoriti khalayak telah menggunakan kata-kata kesat sewaktu menulis komen di dalam media sosial tersebut. Ini jelas menunjukkan bahawa, khalayak telah mengabaikan aspek kesantunan berbahasa ketika berkomunikasi.

Kajian Ainal, Maizatul, Nasihah dan Noor Aida (2016) ini turut disokong oleh Ningsih dan Arianti (2018) serta Kusmanto dan Purbawati (2019) menerusi kajian tentang ketidaksopanan pengikut (followers) memberikan komen. Kajian tersebut mendapati bahawa masyarakat lebih gemar menggunakan komentar kasar dan kesat hingga berbaur hinaan, kecaman serta tidak menunjukkan sebarang kesantunan berbahasa di media sosial. Kajian Ningsih dan Arianti (2018) serta Kusmanto dan Purbawati (2019) dilihat sejajar dengan kajian yang dijalankan oleh Azianura dan Mohammad Rahim (2019) tentang ketidaksopanan 
berbahasa dan etika media sosial yang menyebabkan berlakunya isu-isu negatif seperti buli siber. Hasil kajian tersebut menyatakan etika kebahasaan yang baik perlu dititikberatkan sewaktu berkomunikasi dalam talian kerana mampu mempengaruhi emosi dan mendatangkan kesan buruk seperti kemurungan, hilang keyakinan diri dan sebagainya. Hasil kajian Azianura dan Mohammad Rahim (2019) turut menyokong kajian yang telah dilakukan oleh Wang et al. (2014) tentang penggunaan kata kesat yang digunakan di Twitter. Hasil kajian mendapati bahawa lebih daripada $90 \%$ kekerapan penggunaan kata kesat digunakan sewaktu menulis ciapan di Twitter. Malah, keputusan tersebut juga menunjukkan bahawa peratusan menggunakan kata-kata kesat dalam kalangan lelaki lebih tinggi berbanding dengan wanita.

\section{ANALISIS WACANA DALAM KOMUNIKASI POLITIK}

Kerangka teori merupakan wahana penting bagi setiap kajian yang hendak dijalankan sebagai panduan ketika menganalisis data. Oleh hal yang berikut, kajian ini telah menggunakan teori analisis wacana oleh Normaliza (2019). Teori ini terhasil berdasarkan pendapat dan pandangan yang merujuk kepada teori analisis wacana yang telah dipelopori oleh sarjana barat seperti Stubbs (1983), Brown dan Yule (1983) serta Fairclough (1995). Walau bagaimanapun teori analisis wacana yang diperkenalkan oleh Normaliza (2019) ini telah ditambah baik mengikut norma dan budaya masyarakat di Malaysia.

Secara dasarnya, teori analisis wacana oleh Normaliza (2019) mengandungi tiga elemen iaitu kandungan, konteks dan juga andaian. Elemen kandungan mempunyai satu aspek sahaja iaitu tema. Sungguhpun demikian, aspek tema terbahagi kepada bahan, sampel dan juga jenis. Bahan adalah medium perantaraan yang berupa berperanan sebagai sandaran untuk memulakan sesuatu kajian. Sebagai analoginya, sesebuah kajian pasti mempunyai suatu bahan yang digunakan untuk dijadikan sandaran seperti novel, rencana, filem, akhbar dan sebagainya. Hal ini serupa dengan bahan tentang penceritaan filem yang mengkategorikan tema mengikut kesesuaian filem tersebut seperti tema kekeluargaan, kasih sayang mahupun agama. Seterusnya, sampel pula merujuk kepada peranan yang dimainkan oleh pelaku terhadap sesuatu bahan tersebut. Misalnya, bahan yang digunakan adalah tentang filem yang bertemakan keagamaan manakala sampel yang diambil adalah peranan tentang watak lakonan 'ustaz' dalam filem tersebut. Akhir sekali, adalah jenis. Aspek ini bergantung kepada bahan yang digunakan di dalam sesuatu kajian seperti pidato, cerita, deskriptif, surat dan lain-lain yang akan dihuraikan secara lebih terperinci. Contohnya, di dalam kajian mengenai lagu, bahan yang dipilih adalah lirik lagu tersebut namun jenis lirik lagu boleh terdiri daripada balada, hip hop, klasik dan sebagainya.

Elemen yang kedua dalam teori analisis wacana ini adalah konteks. Menurut Normaliza (2019), elemen konteks mengandungi tiga aspek iaitu tatabahasa, latar dan juga emosi. Aspek pertama iaitu tatabahasa yang menumpukan kepada perkara yang berkaitan dengan pembelajaran tatabahasa terutamanya di dalam bidang linguistik seperti dari segi ejaan, struktur bahasa, imbuhan, kependekan kata dan sebagainya. Aspek kedua ialah aspek latar dan ianya merupakan suatu penemuan baharu yang menjelaskan tentang latar masa, tempat dan juga masyarakat. Misalnya, latar masa akan menerangkan tentang tempoh atau masa yang terjadinya terhadap sesuatu perkara, latar tempat akan menerangkan tentang lokasi dan situasi manakala latar masyarakat akan menerangkan tentang sekumpulan masyarakat mahupun individu yang berada di dalam situasi kajian dijalankan. Aspek terakhir dalam teori ini adalah emosi yang terdapat di dalam Teori Emosi oleh Cannon (1927). Menurut Normaliza (2019), aspek emosi mengandungi tiga lingkungan perasaan iaitu bercampur, 
positif dan negatif. Kesemua emosi ini telah berperanan untuk menjelaskan sesuatu perasaan seperti ketakutan, sedih, gembira dan sebagainya melalui bahan kajian tersebut.

Elemen yang terakhir adalah elemen andaian. Elemen ini telah dipelopori oleh Brown dan Yule (1983) dan terdapat penambahbaikan terhadap beberapa aspek yang terpilih. Aspek yang diketengahkan di dalam elemen andaian ini adalah pendapat, perujuk dan juga persoalan. Bagi aspek pendapat, pengkaji dapat menyatakan pendapat mereka dengan mengandaikan sesuatu perkara itu berlaku terhadap kajian yang dilakukan. Seterusnya rujukan adalah sesuatu perkara yang didasari oleh sesuatu perkara. Misalnya perkataan 'puan' adalah rujukan kepada wanita yang telah berkahwin. Menurut Nurul Afifah Adila (2017) elemen rujukan seringkali berlaku dalam perbualan di antara dua pihak atau lebih. Aspek yang terakhir adalah persoalan. Aspek ini dapat menjawab sesuatu permasalahan yang menimbulkan kekeliruan kepada pembaca lain mahupun pengkaji dengan menggunakan elemen andaian tersebut.

Secara keseluruhannya, kajian ini menggunakan Teori Analisis Wacana oleh Normaliza (2019) sebagai kerangka dan panduan asas dengan mengambil kira beberapa perkara iaitu kandungan dan konteks untuk disesuaikan dengan analisis pola penggunaan bahasa.

\section{METODOLOGI}

Kajian ini telah memilih reka bentuk kualitatif iaitu dengan cara menganalis teks daripada ciapan akaun Twitter @NajibRazak untuk mengetahui pola penggunaan bahasa Malaysia. Justifikasi pemilihan akaun Twitter ahli politik berkenaan telah ditetapkan berdasarkan kepada beberapa kriteria termasuklah bilangan pengikut (follower) yang paling tinggi di Twitter. Akaun Mohd Najib Tun Razak atau (@NajibRazak) merupakan individu paling berpengaruh dan memiliki jumlah pengikut tertinggi di Twitter iaitu berjumlah 4,263,963 orang (Sinar Harian). Tambahan lagi, setelah menilai segala ciapan ciapan Twitter beliau, didapati bahawa subjek sering menggunakan bahasa Melayu berbanding ahli politik yang lain ketika memuat naik ciapan. Akaun Twitter @NajibRazak telah wujud sejak tahun 2008 namun beliau mula aktif memuat naik ciapan pada tahun 2018 setelah kejatuhan kerajaan Barisan Nasional dan pertukaran kerajaan baharu Perikatan Nasional. Walau bagaimanapun, pemilihan ciapan ini akan dibataskan dalam tempoh masa yang telah ditetapkan iaitu daripada November 2018 sehingga Februari 2020. Hal ini disebabkan oleh, Malaysia sekali lagi telah melakukan pembubaran kerajaan pada Februari 2020 untuk menggantikan kerajaan Pakatan Harapan. Ekoran daripada itu, kebanyakan ciapan yang dimuat naik oleh subjek adalah menjurus kepada kritikan terhadap kerajaan Pakatan Harapan. Namun begitu, masih terdapat juga ciapan-ciapan yang berkaitan dengan keagamaan, sosial dan sebagainya.

Sehubungan dengan itu, kajian ini telah menetapkan beberapa tatacara bagi melancarkan analisis data. Langkah awal yang dilakukan setelah memilih subjek adalah membuat pemilihan data berdasarkan ciapan yang dimuat naik untuk memudahkan proses analisis kandungan ciapan berkenaan. Seterusnya, kesemua ciapan tersebut akan dikelaskan kepada tiga tema yang telah ditentukan berdasarkan kehendak kajian iaitu politik, ekonomi dan agama. Bersangkutan dengan tatacara berkenaan, kesemua teks ciapan ini akan dianalisis berpandukan teori analisis wacana oleh Normaliza (2019) yang hanya menggunakan beberapa prinsip sahaja, iaitu untuk disesuaikan dengan kajian terhadap pola penggunaan bahasa. Sebagai tambahan, kesemua data yang diperoleh daripada ciapan @NajibRazak adalah secara verbatim dan tidak diubahsuai agar kajian ini dapat dianalisis dari aspek linguistik. 


\section{HASIL DAN PERBINCANGAN}

Kajian ini dianalisis berpandukan Teori Analisis Wacana oleh Normaliza (2019) yang menekankan tiga elemen wacana iaitu kandungan, konteks, dan andaian. Walau bagaimanapun, ciapan yang dimuat naik oleh @NajibRazak berdasarkan elemen kandungan dan konteks yang hanya menggunakan beberapa prinsip dalam elemen tersebut iaitu tema, latar dan emosi.

Oleh yang demikian, analisis wacana yang dicadangkan oleh Normaliza (2019) telah menetapkan tema sebagai aspek yang perlu ada di dalam elemen kandungan bagi mengelakkan sebarang kekeliruan. Menurut Nurul Aishah, Normaliza dan Nor Azuwan (2018) teks wacana yang baik memenuhi tema yang hendak disampaikan. Seterusnya, konteks dianggap sebagai tindakan mengungkapkan makna di luar makna literal kerana mampu meliputi keseluruhan maklumat yang hendak dikaji. Oleh itu Teori Analisis Wacana oleh Normaliza (2019) telah menetapkan aspek yang perlu ada di dalam elemen kandungan adalah tatabahasa, latar dan juga emosi. Jelaslah, kesemua aspek tersebut perlu dilihat agar keseluruhan konteks dapat dikaji.

Berikut adalah pembahasan mengenai kandungan dan konteks berdasarkan penetapan tema yang dilakukan. Tema paling utama diambil perhatian adalah mengenai ekonomi kerana tema tersebut paling banyak dimuat naik di akaun Twitter milik subjek. Seterusnya adalah berkaitan dengan sosial iaitu peristiwa-peristiwa yang berlaku dalam kalangan masyarakat termasuklah bencana, manakala tema terakhir adalah mengenai agama yang dapat mendatangkan keinsafan kepada pembaca. Walau bagaimanapun, pengkaji telah membataskan tiga ciapan sahaja pada setiap tema yang ditetapkan agar tidak berlaku pertindihan data.

Jadual 1: Ciapan Terhadap Tema Ekonomi

$\begin{array}{cl}\text { Tema } & \text { Ciapan } \\ \text { Ekonomi } & \text { (i). (a) Maka hutang rasmi negara hari ini sudah sampai RM781.4b. (b) Pinjam lagi 18.6b, kita } \\ & \text { cecah hutang RM800b dengan rasminya. (c) Berbanding RM 686b pada akhir 2017 bawah BN. } \\ & \text { (ii). Merujuk data terbaru Jabatan Statistik yang dikeluarkan petang semalam, nilai eksport } \\ & \text { minyak kelapa sawit dan hasil keluaran berasaskan minyak kelapa sawit telah merosot 24.4\% } \\ & \text { untuk keseluruhan tahun } 2018 \text { berbanding tahun 2017. }\end{array}$

(iii). Harga ikan kembong pagi ini di kompleks muhibah kg Pandan RM22 kg. 3 minggu dulu RM 17! Harga makin naik. Adoi.

Jadual 1 di atas menunjukkan ciapan yang dimuat naik di dalam akaun @NajibRazak berdasarkan tema ekonomi. Hal ini jelas ditunjukkan melalui bahasa subjek di dalam kapsyen yang telah menggunakan beberapa istilah ekonomi seperti sejumlah wang, hutang, peratusan yang merosot dan sebagainya. Tema ekonomi yang pertama adalah (i). 'Maka hutang rasmi negara hari ini sudah sampai RM781.4b. Pinjam lagi 18.6b, kita cecah hutang RM800b dengan rasminya. Berbanding RM 686b pada akhir 2017 bawah $B N^{\prime}$. Tema ekonomi (i) dilihat menggunakan gaya bahasa penegasan yang berunsur klimaks iaitu menyatakan sesuatu hal secara umum kemudian beransur menjadi lebih khusus. Oleh itu, penegasan klimaks dalam tema ekonomi (i) dapat dilihat melalui dari turutan umum iaitu: (a) 'hutang rasmi negara sudah sampai RM781.4b'; (b) 'Pinjam lagi 18.6b kita cecah hutang RM800b dengan rasminya'; (c) 'Berbanding RM 686b pada akhir 2017 bawah BN'. Dalam konteks ayat (a), subjek telah menyatakan secara umum tentang bebanan hutang yang sedang dialami oleh negara. Setelah itu, dalam konteks (b), subjek telah mengkhususkan pernyataan tersebut dengan penyebutan penambahan jumlah hutang. Terakhir, iaitu konteks (c) di mana subjek 
telah menegaskan dengan khusus tentang perbandingan hutang yang dialami negara sewaktu pentadbiran kerajaan yang terdahulu. Bertitik tolak daripada tema ekonomi (i), konteks yang terkandung dalam ciapan tersebut secara tidak langsung telah merujuk kepada konteks latar yang menjurus kepada latar tempat iaitu negara Malaysia. Meskipun dalam konteks (i) tersebut tidak menyatakan secara khusus tentang negara Malaysia, namun setelah menyentuh mengenai 'Ringgit Malaysia (RM)' dan 'Barisan Nasional (BN)' jelas menunjukkan latar tempat yang dimaksudkan dalam konteks tersebut adalah negara Malaysia. Hal ini kerana, 'RM' merupakan mata wang yang digunakan di dalam negara Malaysia dan hal yang sama juga berlaku pada frasa nama 'BN' iaitu salah satu daripada parti politik yang telah ditubuhkan di Malaysia. Oleh itu, tema ekonomi (i) telah menjelaskan tentang pola penggunaan bahasa yang dipengaruhi oleh gaya bahasa penegasan klimaks dan turut disesuaikan oleh latar tempat sebagaimana yang terkandung di dalam teori analisis wacana.

Seterusnya adalah tema ekonomi (ii) iaitu 'merujuk data terbaru Jabatan Statistik yang dikeluarkan petang semalam, nilai eksport minyak kelapa sawit dan hasil keluaran berasaskan minyak kelapa sawit telah merosot 24.4\% untuk keseluruhan tahun 2018 berbanding tahun 2017'. Tema ekonomi dalam dalam konteks (ii) telah terjalin sebagai satu wacana berbentuk laporan. Tema ekonomi berbentuk laporan ini jelas terlihat melalui penggunaan kata nama 'statistik', 'merosot' dan juga penggunaan peratusan. Dalam konteks (ii) ini, tema ekonomi yang dinyatakan oleh subjek adalah berkaitan nilai eksport terhadap minyak kelapa sawit negara Malaysia. Tidak hanya itu, dalam konteks ini, subjek telah melakukan perbandingan tahun tentang hasil keluaran minyak sawit dan menyatakan bahawa keberhasilannya telah merosot berbanding tahun sebelumnya. Tambahan lagi, subjek turut menyatakan tentang peratusan susut nilai eksport minyak sawit tersebut telah dirujuk daripada data Jabatan Statistik yang baru sahaja dikeluarkan pada tahun berkenaan.

Melalui beberapa penekanan dalam penulisan ciapan (ii) tersebut telah jelas menunjukkan tema ekonomi. Sehubungan dengan itu, wacana laporan dalam tema ekonomi (ii) ini jelas mempunyai perkaitan dengan latar yang mengkhususkan kepada latar masa. Hal ini dapat dilihat melalui penggunaan perkataan 'tahun 2017' dan '2018'. Ini bermakna, tema ekonomi (ii) yang menjurus kepada nilai minyak kelapa sawit telah berlaku dalam tempoh waktu setahun bagi menjelaskan statistik kemerosotan yang berlaku. Walau bagaimanapun, dalam ciapan tersebut, subjek tidak menyatakan waktu mahupun tarikh data statistik yang diambil secara khusus. Maka dengan itu, latar masa di dalam tema ekonomi (ii) telah memainkan peranan yang utama dalam pola penggunaan bahasa untuk menjelaskan kemerosotan minyak kelapa sawit tersebut.

Tema ekonomi (iii) pula adalah 'Harga ikan kembong pagi ini di kompleks muhibah $\mathrm{kg}$ Pandan RM22 kg. 3 minggu dulu RM 17! Harga makin naik. Adoi'. Tema ekonomi (iii) jelas dilihat melalui penggunaan perkataan tentang harga barangan dan juga perbandingan harga dalam waktu-waktu tertentu. Tambahan lagi, penggunaan bahasa dalam tema ekonomi (iii) telah menunjukkan bahasa yang ringkas namun masih boleh difahami oleh pembaca lain. Subjek juga menggunakan bahasa yang ringkas dan tidak formal namun masih berpandukan kepada etika bahasa supaya dapat membentuk proses realiti sosial dalam kalangan masyarakat serta dapat mengeratkan hubungan masyarakat dengan pemimpin. Hal ini dapat dibuktikan melalui perkataan 'Harga makin naik. Adoi' yang menunjukkan bahasa tidak formal untuk menggambarkan rasa keluhan sama seperti yang dialami oleh rakyat terhadap kenaikan harga barangan basah. Sejajar dengan itu, tema ekonomi (iii) telah menekankan dua konteks yang berbeza iaitu dari segi latar yang menjurus kepada latar tempat di negara 
Malaysia. Hal ini dapat dibuktikan dengan penggunaan mata wang yang menunjukkan Ringgit Malaysia dan juga tempat yang dinyatakan oleh subjek iaitu Kompleks Muhibah, Kampung Pandan. Selain itu, tema ekonomi (iii) juga dipengaruhi oleh konteks emosi sebagaimana yang dijelaskan dalam teori analisis wacana. Walau bagaimanapun, subjek tidak menzahirkan emosinya secara literal. Namun, dapat dilihat melalui penulisan subjek seperti keluhan kerana harga barangan telah meningkat. Ini jelas dengan perkataan yang ditulis oleh subjek dengan menggunakan perkataan 'adoi' untuk menunjukkan keluhan dan juga emosi kecewa. Oleh hal yang demikian, pola penggunaan bahasa dalam tema ekonomi (iii) telah disesuaikan dengan teori analisis wacana yang menekankan konteks latar tempat serta permainan emosi supaya pola bahasa tersebut lebih jelas.

Jadual 2: Ciapan Terhadap Tema Sosial

Tema Ciapan

Sosial (i). Biarlah orang-orang yang nak ganggu, kawal pergerakan saya. Tiada sesiapa boleh menghalang saya berjumpa dengan rakyat. Saya masuk jumpa orang kampung lagi, ziarah Hj. Shari'at Hj. Hussin. Semoga dikurniakan kesihatan yang baik dikurniakan.

(ii). Amat sedih membaca berita mengenai penahanan 47 rakyat Malaysia di Kemboja. Keluarga mereka sedang menunggu mereka pulang ke pangkuan keluarga yang tercinta. Sudah melebihi 1 bulan. Tindakan segera perlu diambil Kerajaan untuk membawa mereka pulang.

(iii). Saya berasa sedih dengan apa yang berlaku di Pasir Gudang ini. Saya mendoakan keadaan akan segera pulih dan mangsa terjejas akan sembuh dalam masa yang paling singkat.

Jadual 2 di atas menunjukkan ciapan yang dimuat naik di dalam akaun @NajibRazak berdasarkan tema sosial. Pemilihan ciapan yang berkaitan dengan tema sosial adalah bersangkutan dengan aktiviti sosial yang telah dilakukan oleh subjek. Antaranya, subjek telah menulis perkara yang berkaitan dengan aktiviti melawat bersama rakyat, keprihatinan, dan juga tanggungjawab sosial. Sehubungan dengan itu, ciapan dalam tema sosial (i) ialah 'Biarlah orang-orang yang nak ganggu, kawal pergerakan saya. Tiada sesiapa boleh menghalang saya berjumpa dengan rakyat. Saya masuk jumpa orang kampung lagi, ziarah $\mathrm{Hj}$. Shari'at Hj. Hussin. Semoga dikurniakan kesihatan yang baik dikurniakan'. Tema sosial (i) tersebut jelas terlihat melalui penggunaan perkataan 'jumpa rakyat', 'jumpa orang kampung' dan juga 'ziarah' bagi menzahirkan sikap keprihatinannya sebagai wakil rakyat kepada masyarakat meskipun terdapat beberapa rintangan. Bersangkutan dengan itu, tema sosial (i) telah ditulis di dalam bentuk kesantunan informasi atau berbentuk pemberitahuan kepada pembaca. Dalam konteks ini, penutur ingin meluahkan perasaan kecewanya kerana telah dihalang untuk melakukan kebaikan namun subjek masih tidak berputus asa dalam perjuangan tersebut. Hal ini dapat ditunjuk melalui perkataan 'Tiada sesiapa boleh menghalang saya berjumpa dengan rakyat'. Lanjutan daripada itu, tema sosial (i) yang menjurus kepada lawatan ziarah penduduk kampung dapat disesuaikan dengan penggunaan dua latar yang berbeza. Latar yang pertama jelas ditonjolkan dalam tema sosial (i) adalah latar masyarakat yang menumpukan masyarakat kampung dan ia dapat dibuktikan melalui perkataan 'orang kampung' yang ditulis oleh subjek. Rentetan dengan latar masyarakat orang kampung, latar kedua yang ditonjolkan di dalam penulisan ciapan ini adalah latar tempat sebagaimana yang ditulis oleh subjek untuk mengadakan lawatan ziarah di kawasan perkampungan. Oleh hal yang demikian, kedua-dua latar yang berbeza-beza ini telah mempengaruhi pola penggunaan bahasa yang telah ditulis oleh subjek terutamanya dalam tema sosial (i). 
Seterusnya, adalah tema sosial (ii) iaitu: (a) 'amat sedih membaca berita mengenai penahanan 47 rakyat Malaysia di Kemboja; (b) Keluarga mereka sedang menunggu mereka pulang ke pangkuan keluarga yang tercinta; (c) Sudah melebihi 1 bulan; (d) Tindakan segera perlu diambil kerajaan untuk membawa mereka pulang'. Tema sosial (ii), jelas kelihatan melalui sikap keprihatinan yang ditonjolkan oleh subjek dengan menyampaikan luahan rasa hati dan pilu terhadap perkara yang menimpa beberapa rakyat Malaysia. Ciapan yang telah dimuat naik oleh subjek adalah tentang penahanan beberapa rakyat Malaysia di Kemboja. Bertitik tolak daripada sikap keprihatinan tersebut, luahan rasa hati subjek jelas dinyatakan di dalam bentuk penulisan hujahan secara induktif di mana satu pernyataan yang khusus telah dinyatakan terlebih dahulu kemudian beransur kepada pernyataan yang lebih umum dan akan berakhir dengan kesimpulan. Penghujahan secara khusus telah dinyatakan oleh subjek terhadap bilangan warganegara yang terperengkap di Kemboja iaitu melalui penyataan (a) kemudian hujahan (i) telah diperkukuh lagi melalui ayat (b) dan (c) dan akhir sekali subjek telah melakukan kesimpulan dalam ayat (d) agar kesemua mangsa tersebut selamat pulang. Bersangkutan dengan hujahan induktif tersebut, pola penggunaan bahasa di dalam tema sosial (ii) telah menunjukkan dua konteks yang berbeza. Konteks pertama telah memperlihatkan emosi negatif iaitu perasaan sedih terhadap tahanan warganegara Malaysia di Kemboja yang telah lama tidak berjumpa dengan ahli keluarga masing-masing. Emosi sedih tersebut dapat dibuktikan melalui penggunaan perkataan 'amat sedih' yang bukan sahaja dirasai subjek malah turut dirasai oleh tahanan dan ahli keluarga mereka. Konteks seterusnya adalah konteks berdasarkan latar yang mengkhususkan latar tempat. Dalam konteks ini, tema sosial (ii) telah menyatakan tempat secara khusus iaitu di negara Kemboja di mana berlakunya penahanan warganegara Malaysia. Justeru itu, jelaslah bahawa pola penggunaan bahasa yang digunakan di dalam tema sosial (ii) telah dipengaruhi oleh dua konteks yang berbeza iaitu konteks emosi yang menjelaskan emosi sedih dan juga konteks latar yang khusus kepada latar tempat.

Terakhir ialah tema sosial (iii) iaitu 'Saya berasa sedih dengan apa yang berlaku di Pasir Gudang ini. Saya mendoakan keadaan akan segera pulih dan mangsa terjejas akan sembuh dalam masa yang paling singkat'. Tema sosial (iii) telah ditulis sebagai sebuah wacana jenis ekspresi dan tema sosial tersebut jelas terlihat melalui penggunaan perkataan 'berasa sedih'. Bersangkutan dengan itu, wacana ekspresi berlaku untuk menyatakan luahan, hasrat atau pendapat pewacana yang berkaitan dengan tiga perkara utama iaitu kenegaraan, ekonomi dan sosial (Idris, 2004). Oleh hal yang demikian, wacana ekspresi di dalam tema sosial (iii) telah menekankan dari sudut sosial kerana teks tersebut menyentuh tentang bencana yang sedang dialami oleh rakyat di Pasir Gudang. Bersangkutan dengan wacana ekspresi, pola penggunaan bahasa di dalam tema sosial (iii) telah menunjukkan konteks emosi yang selaras dengan teori analisis wacana. Oleh itu, konteks emosi tersebut telah menunjukkan emosi sedih dan ia jelas melalui penggunaan perkataan yang ditulis oleh subjek iaitu 'saya berasa sedih'. Dalam pada itu, tema sosial yang menjurus kepada bencana tersebut telah dikhususkan berdasarkan kawasan tertentu sekali gus dapat menunjukkan latar tempat iaitu bencana yang berlaku di Pasir Gudang seperti yang dinyatakan oleh subjek. Oleh itu, jelas bahawa pola penggunaan dalam tema sosial (iii) hampir sama dengan tema sosial (i) dan (ii) yang telah dipengaruhi oleh konteks latar dan juga emosi sebagaimana yang terkandung di dalam teori analisis wacana. 
Jadual 3: Ciapan Terhadap Tema Agama

Ciapan
Tema

(iii). Allah Maha Mendengar, walau sehalus mana bisikan dalam hati yang ikhlas. Jadi jangan pernah berhenti berdoa dan bergantung harap kepada-Nya.

Jadual 3 di atas menunjukkan tema yang terakhir yang dimuat naik di dalam akaun @NajibRazak iaitu tema agama. Pemilihan ciapan tema agama jelas kelihatan melalui penggunaan perkataan yang berkaitan dengan keagamaan seperti seperti Allah SWT, bulan kemuliaan, bersyukurlah dan banyak lagi. Bertitik tolak daripada itu, ciapan di dalam tema agama (i) ialah 'Malam ini tak ke mana-mana, baca yasin di rumah. Kadang kala hidup kita tidak spt dirancang. Tetapi percayalah. Allah SWT mengetahui yang terbaik buat kita, perancang Maha Sempurna. Bersyukurlah. Di saat susah atau senang Allah SWT lindungi kita, beri rezeki, nikmat kpd kita'. Tema agama (i) ditulis di dalam bentuk pesanan kepada pembaca yang berkaitan dengan amalan sebagai seorang muslim yang mukmin dan ia dilihat melalui petikan frasa 'Bersyukurlah'. 'Di saat susah atau senang Allah SWT lindungi kita, beri rezeki, nikmat kpd kita'. Bukan itu sahaja, subjek juga turut berkongsi penulisan tentang informasi keagamaan. Hal ini dapat dilihat apabila subjek mengatakan kehidupan yang dijalani tidak seperti yang dirancang, namun Allah SWT adalah sebaik-baik perancang dan sentiasa mengetahui sesuatu hal yang terbaik buat hamba-Nya. Tambahan lagi, subjek turut memberi nasihat kepada rakyat agar sentiasa bersyukur kerana Allah SWT sentiasa berada di sisi umatNya di dalam segala hal. Tambahan lagi, bagi menguatkan tema agama dalam ciapan (i), penggunaan frasa kerja 'baca yasin' merupakan amalan yang sering dilakukan oleh setiap muslim sebagai tanda kita beriman dan menyuruh segala perintah-Nya tanda mengira waktu. Lantaran itu, pola bahasa dalam tema agama (i) telah jelas menunjukkan dua latar yang berbeza di dalam ciapan wacana tersebut sebagaimana yang terkandung di dalam teori analisis iaitu latar masa dan latar tempat. Bagi latar yang pertama iaitu latar masa, telah berlaku pada waktu malam sebagaimana yang dijelaskan oleh subjek di dalam penulisan ciapan tersebut iaitu 'Malam ini tak ke mana-mana'. Seterusnya, ialah latar tempat yang jelas dinyatakan oleh subjek iaitu latar tempat menunjukkan di rumah dan ia dapat diperkuatkan lagi dengan penulisan subjek iaitu 'baca yasin di rumah'. Oleh hal yang demikian, melalui pola penggunaan terhadap pesanan dalam tema agama (i) jelas mempengaruhi berdasarkan dua konteks latar yang berbeza iaitu latar masa yang menunjukkan waktu malam dan juga latar tempat yang merujuk kepada kediaman subjek.

Seterusnya, tema agama (ii) iaitu 'Allah Maha Mendengar, walau sehalus mana bisikan dalam hati yang ikhlas. Jadi jangan pernah berhenti berdoa dan bergantung harap kepada-Nya'. Jika diperhatikan tema agama (ii), ciapan tersebut telah ditulis dalam bentuk pesanan secara ringkas. Rentetan itu, pesanan yang disampaikan oleh subjek adalah tidak berhenti meminta pertolongan dan doa kepada Allah dan subjek memberitahu walaupun doa yang tersebut sehalus bisikan, Allah tetap dapat mendengar doa umat-Nya. Dalam pada itu, tema agama (ii) telah ditulis dalam bentuk ayat perintah jenis larangan. Hal ini jelas dapat dibuktikan melalui penggunaan perkataan 'jangan' yang menjelaskan bahawa subjek tidak mahu seseorang itu berhenti berdoa dan berharap kepada Allah S.W.T. Dalam konteks ini, 
ayat larangan yang diujar oleh subjek adalah berbentuk positif kerana mahu seseorang itu untuk sentiasa berdoa. Oleh hal itu, pola bahasa dalam tema agama (ii) jelas dipengaruhi oleh bentuk ayat perintah jenis larangan untuk menjelaskan dengan lebih terperinci tentang pesanan yang disampaikan oleh subjek.

Tema agama terakhir adalah berdasarkan ciapan (iii) iaitu 'esok dah start puasa ya. Jangan lupa! Selamat menunaikan puasa. Semoga Allah menerima segala amal ibadah kita pada bulan yang penuh kemuliaan dan barakah ini'. Ciapan keagamaan ini adalah peringatan tentang puasa. Subjek turut mengucapkan selamat berpuasa dan berharap agar segala amalan yang dilakukan sepanjang bulan Ramadhan diterima oleh Allah. Tema agama dalam ciapan (iii) jelas ditunjukkan melalui penggunaan laras bahasa agama, misalnya perkataan 'puasa', 'Allah', 'ibadah' dan 'barakah'. Kesemua penggunaan kata nama tersebut telah merujuk kepada amalan dan perbuatan yang sering dijalani oleh masyarakat khususnya umat Islam sebagai tanda mentaati perintah dan suruhan Allah. Tambahan lagi, tema agama (iii) dapat dijelaskan lagi melalui penggunaan kata nama 'ibadah' berdasarkan istilah dari bahasa Arab yang bermaksud ibadat iaitu amalan atau perbuatan yang dilakukan untuk berbakti kepada Tuhan. Tidak hanya itu, subjek juga turut menggunakan perkataan 'barakah' yang membawa makna memperoleh reda daripada Allah. Bersangkutan dengan itu, pola penggunaan bahasa dalam tema agama bagi ciapan (iii) telah menunjukkan penggunaan latar masa sebagaimana yang terkandung dalam teori analisis wacana. Latar yang ditunjukkan dalam ciapan (iii) tidak dinyatakan secara khusus, namun pembaca dapat mengetahui bahawa latar masa dalam konteks peristiwa tersebut berlaku pada bulan Ramadhan. Hal ini kerana, subjek telah menyatakan beberapa kali isu yang menyentuh tentang 'puasa' dan aktiviti tersebut hanya berlaku pada bulan Ramadhan berdasarkan kalender Islam. Oleh hal yang demikian, pola penggunaan bahasa dalam tema agama (iii) telah dipengaruhi oleh latar masa sahaja yang merujuk pada bulan puasa.

\section{KESIMPULAN}

Secara keseluruhannya, akaun Twitter @NajibRazak tidak hanya berkongsi ciapan berteraskan tema politik sahaja, meskipun subjek merupakan seorang ahli politik. Tambahan lagi, kandungan ciapan yang sering dimuat naik oleh subjek terdiri daripada pelbagai tema misalnya agama, keprihatinan, sosial, dan ekonomi. Walau bagaimanapun, kajian ini tidak menyentuh isu yang berkaitan dengan politik malah telah menganalisis dari aspek yang berbeza dengan mengambil kira ciapan berdasarkan tema ekonomi, sosial dan juga agama.

Kesimpulannya, berdasarkan tiga tema yang telah dianalisis, pemilihan pola bahasa yang digunakan adalah hampir sama. Namun perbezaannya hanya jelas ditunjukkan melalui beberapa perubahan konteks sebagaimana yang terkandung di dalam teori analisis wacana yang merangkumi tatabahasa, konteks dan juga emosi. Pola penggunaan bahasa dalam tema ekonomi berlaku akibat daripada beberapa perubahan yang signifikan iaitu penegasan klimaks, wacana berbentuk laporan dan penggunaan bahasa ringkas. Perubahan tersebut telah dipengaruhi oleh konteks emosi yang merujuk kepada ciapan (iii) dan juga konteks latar yang mengkhususkan latar tempat dan masa dalam keseluruhan tema ekonomi tersebut.

Seterusnya, pola penggunaan bahasa dalam tema sosial berubah berdasarkan kesantunan informasi, hujahan induktif, dan wacana ekspresi serta perubahan tersebut dilihat mempunyai persamaan dengan tema ekonomi kerana dipengaruhi oleh dua konteks yang berbeza iaitu konteks emosi dan juga konteks latar yang juga mengkhususkan kepada latar tempat dan masa. 
Tema terakhir iaitu, tema agama telah menunjukkan perubahan pada pola penggunaan bahasa iaitu wacana berbentuk pesanan. Penggunaan laras serta perubahan tersebut telah dipengaruhi oleh konteks latar sahaja dengan memfokuskan kepada latar masa dan latar tempat sebagaimana yang telah dijelaskan dalam ciapan tersebut. Dengan ini, ternyata penggunaan media sosial terutamanya Twitter telah membentangkan ruang kepada ahli politik untuk melontarkan idea, menyatakan pendapat, mahupun menzahirkan perasaan. Hasil kajian menunjukkan bahawa ahli politik bebas dan berani untuk menyatakan hasrat mereka baik isu yang menyentuh soal politik mahupun tidak. Walau bagaimanapun, mereka masih terikat dengan sistem perundangan yang membataskan mereka untuk menyemaikan sifat akauntabiliti dan bertanggungjawab terhadap sesuatu, melalui penulisan ciapan mereka.

\section{BIODATA}

Nur Firza Shafiqa binti Khalid merupakan pelajar sarjana yang mengikuti program Master Sastera (Bahasa Melayu) di Universiti Putra Malaysia. Beliau sedang mengkaji bidang wacana dalam media sosial ahli politik. Email: firzashafiqa@gmail.com

Normaliza Abd Rahim (PhD) merupakan Profesor bahasa, media, teknologi dan kajian wacana di Jabatan Bahasa Melayu, Fakulti Bahasa Moden dan Komunikasi, Universiti Putra Malaysia. Email: nliza@upm.edu.my 


\section{RUJUKAN}

Abdul Halim Ahmad, \& Mohd Najib Husin. (2016). Penggunaan aplikasi rangkaian sosial dalam kalangan pelajar politeknik Kuala Terengganu. Politeknik \& Kolej Komuniti Journal of Social Sciences and Humanities, 1(1), 81-90.

Agbo, I., Kadiri, G., \& ljam, B. (2018). Critical metaphor analysis of political discourse in Nigeria. English Language Teaching, 11(5), 95-103.

Ainal Akmar Ahmad, Maizatul Azura Yahya, Nasihah Hashim, \& Noor Aida Mahmor (2016). Kesantunan bahasa semasa berkomunikasi di laman sosial. Proceeding of the International Conference on Government \& Public Affair 2016 (ICOGPA2016). UUM.

Ali Salman, Mohammad Agus Yusoff, Mohd Azul Mohamad Salleh, \& Mohd Yusof Abdullah. (2018). Pengunaan media sosial untuk sokongan politik di Malaysia. JONUS: Journal of Nusantara Studies, 3(1), 51-63. https://doi.org/10.24200/jonus.vol3iss1pp51-63

Anshari, F. (2013). Komunikasi politik di era media sosial. Journal Komunikasi, 8(1), 91-102.

Azianura Hani Shaari, \& Mohammad Rahim Kamaluddin. (2019). Buli siber: Ketidaksantunan bahasa dan etika media sosial dalam kalangan remaja Malaysia. e-Bangi: Journal of Social Science and Huminities, 16(6), 1-16.

Azleen Abdul Rahim. (2018, Januari 9). Kewujudan fungsi baharu Twitter beri persaingan di media sosial. Utusan Malaysia.

Coltekin, C. (2020). A corpus of Turkish offensive language on social media. Proceedings of the 12th Conference on Language Resources and Evaluation (LREC 2020), 6174-6184.

Dollarhide, M. (2019). Social media. Investopedia. https://www.investopedia.com/terms.asp

Fatanti, M. N. (2014). Twitter dan masa depan politik Indonesia: Analisis perkembangan komunikasi politik lokal melalui internet. Jurnal IImu Pengetahuan dan Teknologi Komunikasi, 16(1), 17-30.

Fatimah Ahmad, \& Ali Salman. (2015). Partisipasi politik belia secara 'online' melalui ruang demokrasi maklumat media baru. Jurnal Komunikasi: Malaysian Journal of Communication, 31(1), 81-10.

Fazlinda Ab Halim, \& Mohammad Siraj Munir Muslaini. (2018). Impak media sosial terhadap tingkah laku sosial pelajar di kolej vokasional. Online Journal for TVET Practitioners, 3(1), 87-94.

Fornara, F., \& Lomicka, L. (2019). Using visual social media in language learning to investigate the role of social presence. CALICO Journal, 36(3), 184-203.

Fuzirah Hashim, Ahmad Aminuddin Soopar, \& Bahiyah Abdul Hamid. (2017). Linguistic features of Malaysian students' online communicative language in an academic setting: The case of Universiti Kebangsaan Malaysia. Akademika, 87(1), 231-242.

Harrera, A. E. P. (2016). Pemanfaatan media sosial Twitter oleh Ridwan Kamil dan Ganjar Pranowo telah sesuai dengan fungsi utama media massa. Jurnal The Messenger, 8(2), 52-60. http://dx.doi.org/10.26623/themessenger.v8i2.335

Hidayatullah, A. F. (2016). Twitter sebagai media dakwah. Teknoin: Jurnal Teknologi Industri, 22(1), 38-43.

Idris Aman. (2004). Bahasa dan kepimpinan: Pengkhalayakan wacana Perdana Menteri Dato' Seri Dr. Mahathir Mohamad. Akademika, 65(1),3-25.

Kee Man Chuah. (2013). Aplikasi media sosial dalam pembelajaran bahasa Inggeris: Persepsi pelajar universiti. Issues in Language Studies, 2(1), 56-63. 
Khusnul Hanafi, \& Mohd. Helmi Abd Rahim. (2017). Penggunaan media sosial dan faktorfaktor yang mempengaruhi terbentuknya gerakan sosial oleh pemimpin pelajar universiti di Bandar Pekan Baru, Riau, Indonesia. e-Bangi: Journal of Social Science and Humanities, 12(2), 87-101.

Kusmanto, H., \& Purbawati, C. (2019). Ketidaksopanan berkomentar pada media sosial Instagram: Studi politikopragmatik. Jurnal Kata: Penelitian Tentang IImu Bahasa dan Sastra, 3(2), 217-227.

Maulina, G., \& Darmawan, F. (2015). Peran media sosial Twitter dalam memenuhi motif mahasiswa. Prosiding Jurnalistik SPeSIA, 1(2), 12-20.

Mohd Sufiean Hassan, Noor Jeffri Abdul Wahab, Norli Yusuf, Siti Nurshahidah Sah Allam, Maizura Manshor, \& Abdul Rauf Ridzuan. (2017). Penggunaan media sosial dan hubungan tingkah laku yang dirancang terhadap pemilihan ke institusi pengajian tinggi. Jurnal Sains Sosial: Malaysian Journal of Social Science, 2(1), 55-72.

Mohd Zuwairi Mat Saad, \& Normah Mustafa. (2016). Kandungan mesej Twitter oleh ketua parti politik semasa pilihan raya negeri Sarawak 2016. e-Bangi: Journal of Social Science and Humanities, 11(2), 406-426.

Ningsih, A. R., \& Arianti, R. (2018). Penggunaan disfemisme oleh haters dalam Instagram pada akun artis MJ: Kajian pragmatik. Seminar Nasional Universitas Pasir Pengajaran, 471177.

Noraien Mansor, \& Normaliza Abd Rahim. (2019). Eh!!! Media sosial. Kuala Nerus, Terengganu: Penerbit UMT.

Noraien Mansor, \& Normaliza Abd Rahim. (2019). Instagram in ESL classroom. Man In India, 97(20), 107-114.

Normaliza Abd Rahim. (2018). Discourse analysis theory: A new perspective in analysis. IUKL Research Journal, 6(1), 1-6.

Normaliza Abd Rahim. (2019) Kajian wacana dan strategi komunikasi. Teori dan aplikasi. Terengganu: Penerbit UMT.

Normaliza Abd Rahim, Awang Azman Awang Pawi \& Nik Rafidah Nik Muhamad Affendi (2018) Integration of Values and Culture in Malay Folklore Animation. Pertanika J. Soc. Sci. \& Humanities, 26(1), 359-374.

Nurul Aishah Mohd Radzi, Normaliza Abd Rahim, \& Nor Azuwan Yaakob. (2018). Wacana tekstual dalam iklan selebriti. Jurnal Komunikasi: Malaysian Journal of Communication, 34(4), 198-213.

Nurul Riduan Nor Ashaha, Ridauddin Daud, \& Liza Mokhtar. (2020, March 8). Najib dominisasi media sosial di Malaysia. Sinar Harian. Retrieved from https://www.sinarharian.com.my/article/72943/LAPORAN-KHAS/

Pratiwi, A. A. M. (2020). Peran media sosial dalam meningkatkan penjualan online saat pandemi Covid-19. Jurnal Satyagraha, 3(2),73-81.

Sa'adiah Ma'alip. (2015). Pemilihan bahasa dalam komunikasi di laman sosial. Jurnal Komunikasi: Malaysian Journal of Communication, 31(2), 231-246.

Siti Ezaleila Mustafa. (2016). Pengguna laman sosial dan impaknya terhadap hubungan persahabatan dalam talian. Jurnal Komunikasi: Malaysian Journal of Communication, 32(2), 65-81.

Sitompul, D. A. N. (2015). Media sosial Twitter sebagai pembentuk pemikiran politik mahasiswa (Studi analisis wacana sara mills pada mahasiswa Fakultas IImu Sosial dan IImu Politik Usu). Jurnal IImu Komunikasi FLOW, 6(2). 
Susanto, E. H. (2017). Media sosial sebagai pendukung jaringan komunikasi politik. Jurnal ASPIKOM, 3(3), 379-389.

Utomo, W. P. (2013). Menimbang media sosial dalam marketing politik di Indonesia: Belajar dari Jokowi-Ahok di Pilkada DKI Jakarta 2012. Jurnal Ilmu Sosial dan IImu Politik, 17(1), 67-84.

Wan Amizah Wan Mahmud, \& Muhammad Adnan Pitchan. (2017). Media baharu dan Institusi Raja di Malaysia: Kes penghinaan raja-raja di media sosial. Jurnal Komunikasi: Malaysian Journal of Communication, 33(1), 406-422.

Wang, W., Chen, L., Thirunarayan, K., \& Sheth, A. P. (2014). Cursing in English on Twitter. Proceedings of the 17th ACM Conference on Computer Supported Cooperative Work \& Social Computing, 415-424.

Wulansari, I. (2014). Artikulasi komunikasi politik Ridwan Kamil dalam media sosial Twitter. ULTIMA Comm: Jurnal IImu Komunikasi, 6(2), 20-40. https://doi.org/gdr8 